\title{
Disasterization: A Simple Way to Fix the Asset Pricing Properties of Macroeconomic Models
}

\author{
Xavier Gabaix \\ NYU Stern, CEPR and NBER
}

July $1,2010^{*}$

\begin{abstract}
A central difficulty in economics is to create a model economy that has both good business cycle properties and good asset pricing properties. Macro models have the former, fail in the latter. Finance models typically work with endowment economies, and are hard to integrate with macro. I show how to solve this difficulty by a simple, portable, modelling device, the "disasterization" procedure. Take an economy with good business cycle properties, and create a new, "disasterized" economy, which is essentially identical to the original one, except that, disasters can destroy part of the capital stock and productivity. In the disasterized economy, asset prices exhibit high and volatile risk premia, but investment, employment, the short-term real interest rate remain the same as in the original economy. Hence, we have a tractable unified framework to think about both the macroeconomy and the financial side. As an application, I consider a long-standing difficulty in macro-finance, Tobin's $Q$. In the model, like in the real world, stock market valuations $(Q)$ are very volatile, negatively correlated with future stock returns, but uncorrelated with investment. I conclude by showing
\end{abstract}

*xgabaix@stern.nyu.edu. For helpful conversations and comments, I thank seminar participants at Duke, the IMF, Federal Reserve Board, MIT, NYU, the 2007 Texas Finance Festival. I thank the NSF for support. This paper started circulating in January 2007, as part of Gabaix (2007), which splitted into Gabaix (2010) and the present paper. 
how disasterization procedure can be useful to fix the asset pricing properties of other models, e.g. economies with monetary frictions. 


\section{Introduction}

This paper proposes a simple way to fix the asset pricing properties of traditional macroeconomic models by adding the possibility of disasters in those economies. I start from a traditional economy without disaster. I create a new economy, which has the possibility that disasters will affect productivity the capital stock, but is otherwise identical (except for the rate of time preference, for reasons that will be clear later). I call this process the "disasterization" of the original economy. The new "disasterized" economy behaves exactly like the original economy, except for asset prices. This is to say that GDP, employment, savings, investment, etc. are the same except that they are scaled down if disasters have occurred. However, asset prices, which reveal the possibility of disasters, are different: the equity premium is higher, and, if inflation goes up in a disaster (an assumption which we will discuss), we obtain a positively sloped yield curve and positive bond risk premia.

Hence, this paper shows a simple, practical way to create economies enriched by risk premia: add disasters in the right places, i.e., disasterize economies.

This key idea is simply a starting point from where several useful directions can be taken. First, one can enrich the model with a reasonably realistic model of stocks and bonds - this is what I am doing in this paper. Second, one can study a case where the fall in capital, and the fall in productivity, are not exactly equal. This is the route chosen by Gourio (2009), which studies Epstein-Zin preferences as well. Gourio also finds that a variable disaster risk can be formally equivalent to a time-preference shock. Third, one could use this device to analytically study small changes in disaster probability or intensity and their impact on the macroeconomy.

The idea of disasterization gives a concrete, fairly general way to fix the asset pricing properties of macroeconomic models without losing tractability. Hence, it brings us closer to the goal of a unified model of macro-finance. Some relevant papers on this matter include Jermann (1998), Boldrin, Chritiano and Fisher (2001), and Uhlig (2007). A common theme in those models is that it is hard to have a stable interest rate and a varying equity premium (van Binsgergen, Fernandez-Villaverde, Koijen, Rubio-Ramirez 2010). ${ }^{1}$

\footnotetext{
${ }^{1}$ The reason for this difficulty is in part technical (models become complicated), in part linked to the
} 
However, this task becomes easy with the disasterization procedure. The reason is that it glues two strands of modelling that are quantitatively reasonably successful (at least compared to prior models): the RBC (or New Keynesian) modeling of business cycle, and the disaster literature. In its simplest incarnation (the one presented in this paper), it modifies the two parts just enough so that they fit together, but otherwise leaves them largely intact. Hence, it inherits the reasonably good fit of the macro side from the "pure" macro models (those that give up on asset prices) and the "pure" finance models (with endowment economy, which give up on production). It glues production and asset prices in a seamless way.

This paper borrows from the disaster literature as formulated by Rietz (1988), extended by Longstaff and Piazzesi (2004), and revived by Barro (2006), who used a large panel of countries and found that empirical disasters are large enough to account the equity premium. As this paper wishes to maximize tractability so that the economics can be transparent, it uses the modelling tools developed in Gabaix (2009) for linearity-generating processes and Gabaix (2010) for a concrete disaster economy with time-varying disasters. Noteworthy contributions that use a somewhat richer setup (such as Epsein-Zin utilities) include Gourio (2008) and Wachter (2009).

There are arguably three paradigms for rational, representative-agent economies: habits (Abel 1990, Cambell-Cochrane 1999), long run risks (Epstein and Zin 1989, Bansal and Yaron 2004), and disasters. All three types of models are usually developed in endowment economies. However, it is hard to extend habits and long-run risks models to production economies, in part because they do not use the same CRRA utility function as the basic macro models. However, the basic disaster model does; hence, it can easily be glued to macro models. This is what I do here.

We now have a tractable model. What do we do with it? One dimension is to use the model to mimic the real economy with both asset and goods prices as well as quantities. We

economics of the model. Take for instance the habit model: with an endowment economy, there can be states of the world where the agent is close to "starvation," (i.e., be very near his habit-inducted subsistence level); those states of the world have high marginal utility, hence matter a lot for asset pricing. However, suppose you add the possibility of production and storage: then, agents will want to store goods for those high-marginal utility states; they will have more consumption available in those states, this way undoing the potency of the mechanism. 
can now understand various features of the data. For instance, consider the following longstanding puzzle: why does the stock market $Q$ vary so much, with essentially no relation with aggregate investment (see the references in Philippon 2009)? This paper shows that this is exactly what the model delivers, given that stocks are a capitalization of rents. Other puzzles concern the slope of the yield curve (why is is typically positive, unlike most macroeconomic models) and stock market predictability. (For those, the model simply inherits the explanation given in Gabaix 2010).

Another application is to study perturbations around this basic model. For instance, suppose that the disaster probability rises, what happens to the various economic quantities? Suppose that stock market valuations go up, what happens to investment and GDP? I note that those perturbation studies are possible only when we depart from a simple tractable model.

The paper proceeds as follows. Section 2 presents the basic idea. Section 3 shows how this idea can be immersed in an ambient economy with richer bond and stock prices. Section 4 illustrates the disasterization procedure in other economies, with money, sticky prices, or habits. Section 5 presents some conclusions.

\section{Model Setup}

\subsection{Macroeconomic Environment}

I start from a real business cycle model that can generate realistic macro dynamics, fix it, and get a new economy with the same business cycle properties but different asset pricing properties. To illustrate the procedure, let me use a simple example.

The original economy. The utility function is a conventional, homogenous of degree $1-\gamma$ in consumption:

$$
\max _{L_{t}, C_{t}, K_{t}} \mathbb{E}_{0}\left[\sum_{t=1}^{\infty} \rho_{0}^{t} \frac{C_{t}^{1-\gamma}}{1-\gamma} \phi\left(L_{t}\right)\right]
$$

The production function is $Y=(A L)^{\beta} K^{1-\beta}$. Here the aggregate productivity $A$ is the Solow-labor augmenting one (so that in the long run, $K$, is proportional to $A$ ). I divided it 
as $A_{t}=a_{t} e^{x_{t}}$, where $a_{t}$ is the permanent part of productivity:

$$
a_{t+1}=e^{g} a_{t}
$$

and $x_{t}$ is a transitory disturbance:

$$
x_{t+1}=\rho x_{t}+\eta_{t+1} .
$$

The capital accumulation process follows:

$$
K_{t+1}=\left(a_{t} e^{x_{t}} L_{t}\right)^{\beta} K_{t}^{1-\beta}-C_{t}+(1-\delta) K_{t}
$$

Applying the disaterization procedure. We construct a new economy, that includes the possibility of disasters. If the disaster hits (which has probability $p_{t}$ ), the capital stock is multiplied by a factor $B_{t+1}$, which can be though of as less than 1 . For instance, if the disaster destroys $20 \%$ of the capital stock, $B_{t+1}=0.8$. It is useful to use the notation:

$$
\Delta_{t+1}= \begin{cases}1 & \text { if there is no disaster at } t+1 \\ B_{t+1} & \text { if there is a disaster at } t+1\end{cases}
$$

for some $B_{t+1}>0$. Hence, the law of motion for capital is:

$$
K_{t+1}=\left[\left(a_{t} e^{x_{t}} L_{t}\right)^{\beta} K_{t}^{1-\beta}-C_{t}+(1-\delta) K_{t}\right] \cdot \Delta_{t+1}
$$

I will also propose that the permanent part of productivity falls, by the same amount:

$$
a_{t+1}=e^{g} a_{t} \cdot \Delta_{t+1}
$$

while the transitory disturbance is not affected:

$$
x_{t+1}=\rho x_{t}+\eta_{t+1} .
$$

In the original economy, $\Delta_{t+1}=1$ at all dates. 
A disaster affects the capital stock and the productivity by the same amount. This makes the economics very convenient: suppose that the economy was on its balanced growth path before the disaster. After the disaster, both the capital stock and productivity are scaled down by $20 \%$. Hence, right after the disaster, the economy is again on its new balanced growth path: it is the same as before, except that all "scale" variables (capital, productivity, wages) are permanently scaled down by $20 \%$.

This assumption of common shock to productivity and capital is largely for expediency: - the spirit of this paper is to highlight a particularly clean class of situations. I view the assumption as rather defensible though. A drop in productivity can come from the disruptions (e.g. political, institutional) resulting from disasters. Also, the existence of mean reversion after a disaster is disputed: Cerra and Saxena (2008) find no recovery after various financial crises, and Barro, Nakamura, Steinsson, and Ursua (2009) find only partial recoveries. On top of that, exisiting data suffer from an optimistic selection bias: the ex post worse countries (e.g. Russia after 1917, China after 1945) are not in the sample. All in all, given that for parsimony it is better to assume either full or zero recovery, I submit that the cleanest serviceable benchmark is the one where productivity and capital fall by the same amount.

Finally, the utility function is:

$$
\max _{L_{t}, C_{t}, K_{t}} \mathbb{E}_{0}\left[\sum_{t=1}^{\infty} \rho^{t} \frac{C_{t}^{1-\gamma}}{1-\gamma} \phi\left(L_{t}\right)\right]
$$

except that the rate of time preference $\rho$ is different; it is:

$$
\rho=\rho_{0} \mathbb{E}\left[\Delta_{t}^{1-\gamma}\right]
$$

so that, if $\gamma>1$, agents in the disastized economies are less patient than in the no-disaster economy. The reason is the following: because there are disasters, ceteris paribus, agents want to save more to create a buffer for disaster. To undo this effect, I make them more impatient. Hence, the savings rate in the new and the old economy will be exactly the same, provided the impatience is judiciously chosen, equation (). 
The key result is the following. ${ }^{2}$

Proposition 1 The above disasterized economy can be solved in the following two-step procedure (1) Solve for the " 0 " economy with no disasters, i.e. with $\forall t, \Delta_{t}=1$ and a rate of time preference $\rho_{0}$. Call $C_{t}^{0}, K_{t}^{0}, a_{t}^{0}, L_{t}^{0}, X_{t}^{0}$ the solution for each $t$. (2) Then, the solution of the disasterized economy 1 is

$$
\begin{aligned}
\left(C_{t}, K_{t}, a_{t}\right) & =\left(\mathcal{D}_{t} C_{t}^{0}, \mathcal{D}_{t} K_{t}^{0}, \mathcal{D}_{t} a_{t}^{0}\right) \\
\left(L_{t}, X_{t}\right) & =\left(L_{t}^{0}, X_{t}^{0}\right)
\end{aligned}
$$

where $\mathcal{D}_{t}$ is the cumulative disaster:

$$
\mathcal{D}_{t}=\Delta_{1} \ldots \Delta_{t}
$$

In other terms, the extensive variables $\left(C_{t}, K_{t}, a_{t}\right)$ are scaled by $\mathcal{D}_{t}$, while the intensive variables $\left(L_{t}, X_{t}\right)$ are left unchanged.

To see the logic, it is helpful to state a more general proposition.

Proposition 2 Consider a more general macroeconomic model, where agents maximize utility (6) subject to the initial state variables $\left(K_{0}, a_{0}, x_{0}\right)$, and state variables follow:

$$
\begin{aligned}
K_{t+1} & =G\left(a_{t} e^{x_{t}} L_{t}, C_{t}, K_{t}, x_{t}\right) \Delta_{t+1} \\
a_{t+1} & =a_{t} g\left(\eta_{t+1}, x_{t}\right) \Delta_{t+1} \\
x_{t+1} & =X\left(\eta_{t+1}, x_{t}\right)
\end{aligned}
$$

where $x_{t}$ is a vector of "intensive" factors (e.g. a deviation from trend), $\eta_{t+1}$ is an i.i.d. vector of shocks. $F$ is homogenous of degree 1 in $\left(a_{t} L_{t}, C_{t}, K_{t}\right)$, for instance the neoclassical capital accumulation equation:

$$
G(a L, C, K, x)=\left(e^{x} a L\right)^{\beta} K^{1-\beta}+(1-\delta) K-C
$$

\footnotetext{
${ }^{2}$ The result was in Gabaix (January 2007). It has been also formulated in a paper that started circulating in Feburary 2009, Gourio (2010). That paper contains a host of different material.
} 
Then, Proposition 1 holds true.

Proof. It is immediate to verify that $\left(C_{t}^{0}, K_{t}^{0}, a_{t}^{0}, L_{t}^{0}, X_{t}^{0}\right)$ satisfy the technological constraint of the problem $P^{0}$ (for the 0 economy) if and only if $\left(C_{t}, K_{t}, a_{t}, L_{t}, X_{t}\right)$ satisfy that of the problem $P$. Next, call $V\left(K_{t}, a_{t}, X_{t}\right)$ the value function of the $P$ problem, and $V^{0}\left(K_{t}^{0}, a_{t}^{0}, X_{t}^{0}\right)$ the value function of the $P^{0}$ problem. We have:

$$
\begin{aligned}
V\left(K_{t}, a_{t}, X_{t}\right) & =\max _{C, L} u\left(C_{t}, L_{t}\right)+\rho \mathbb{E}_{t}\left[V\left(K_{t+1}, a_{t+}, X_{t+1}\right)\right] \\
V^{0}\left(K_{t}^{0}, a_{t}^{0}, X_{t}^{0}\right) & =\max _{C, L} u\left(C_{t}^{0}, L_{t}^{0}\right)+\rho_{0} \mathbb{E}_{t}\left[V^{0}\left(K_{t+1}^{0}, a_{t+1}^{0}, X_{t+1}^{0}\right)\right]
\end{aligned}
$$

As is well-known, $V^{0}$ is homogeneous of degree $1-\gamma$ in $\left(K^{0}, a^{0}\right)$.

Consider the value function for problem $P, v(K, a, X)=V^{0}(K, a, X)$, with policy $c=c_{0}$, $L=L_{0}$. We will show that $v$ is the value function $V$, optimal in the $P$ economy. Given:

$$
\begin{aligned}
\rho \mathbb{E}_{t}\left[v\left(K^{\prime}, a^{\prime}, X^{\prime}\right)\right] & =\rho \mathbb{E}_{t}\left[v\left(K_{0}^{\prime} \Delta^{\prime}, a_{0}^{\prime} \Delta^{\prime}, X_{0}^{\prime}\right)\right]=\rho \mathbb{E}_{t}\left[\Delta^{\prime 1-\gamma} v\left(K_{0}^{\prime}, a_{0}^{\prime}, X_{0}^{\prime}\right)\right] \\
& =\rho \mathbb{E}\left[\Delta^{\prime 1-\gamma}\right] \mathbb{E}\left[v\left(K_{0}^{\prime}, a_{0}^{\prime}, X_{0}^{\prime}\right)\right]=\rho_{0} \mathbb{E}\left[v\left(K_{0}^{\prime}, a_{0}^{\prime}, X_{0}^{\prime}\right)\right]
\end{aligned}
$$

we see that $v$ satisfies the Bellman equation (8). By unicity of the solution, we have that $v$ is the optimal policy of problem $P$.

To complete the Proposition, we just need to verify the announced values of the policy variables. Observe that in the $P^{0}$ problem, the optimal policy has $c_{0}=c_{0}\left(K_{0}, a_{0}, X_{0}\right)$, with $c_{0}(\cdot)$ homogenous of degree 1 in $\left(K_{0}, a_{0}\right)$, and $L_{0}=L_{0}\left(K_{0}, a_{0}, X_{0}\right)$, with $L_{0}$ homogenous of degree 0 in $\left(K_{0}, a_{0}\right)$. This completes the proof.

So, "macro" (investment, labor, capital,consumptions) variables don't change at all, but asset prices change.

So we can derive yield curve, stock prices etc., while keeping the macro side constant. This is illustrated more in depth in the next section.

I note that this "equivalence" result is in the spirit of Hansen, Sargent and Tallarini (1999) and Tallarini (2000). However, it is different in many respects, particularly because it concerns disasters and a macroeconomic environment. 


\section{Bond and Stock Prices}

\subsection{Bond prices}

Consider the price of a bond in such an economy. We assume that bond dynamics are as in Gabaix (2010), whose setup I reproduce here. Trend inflation is $I_{t}$. The real value of money (i.e., the inverse of the price level) is called $Q_{t}$ and evolves as:

$$
\frac{Q_{t+1}}{Q_{t}}=\left(1-I_{t}\right) \times \begin{cases}1 & \text { if there is no disaster at } t+1 \\ F_{\$, t+1} & \text { if there is a disaster at } t+1\end{cases}
$$

Hence, in normal times the real value of money depreciates by the rate of inflation, $I_{t}$. Following Barro (2006), there is possibility of default in disasters, where severity is indexed by the recovery rate $F_{\$, t+1} \geq 0 . F_{\$, t+1}=1$ means full recovery and $F_{\$, t+1}<1$ means partial recovery. The default could be an outright default (e.g., for a corporate bond) or perhaps a burst of inflation that increases the price level and thus reduces the real value of the coupon. In this first pass I assume the case where $H_{\$}=p_{t}\left(\mathbb{E}_{t}\left[F_{\$, t+1} B_{t+1}^{-\gamma}\right]-1\right)$ is a constant. In the calibration, I assume $p_{t}, F_{\$, t+1}$ and the distribution of $B_{t+1}$, to be constant. Relaxing this assumption is easy but is not central to the economics, so I do not do it here. Economically, I assume that most variations in the yield curve come from variation in inflation and inflation risk, not in the changes in the probability and severity of disasters.

I decompose inflation as $I_{t}=I_{*}+\widehat{I}_{t}$, where $I_{*}$ is its constant part and $\widehat{I}_{t}$ is its variable part. The variable part of inflation follows the process:

$$
\widehat{I}_{t+1}=\frac{1-I_{*}}{1-I_{t}} \cdot\left(e^{-\phi_{I}} \widehat{I}_{t}+1_{\{\text {Disaster at } t+1\}} J_{t}\right)+\varepsilon_{t+1}^{I}
$$

where $\varepsilon_{t+1}^{I}$ has mean 0 and is uncorrelated with the realization of a disaster.

This equation means first that if there is no disaster, $\mathbb{E}_{t} \widehat{I}_{t+1}=\frac{1-I_{*}}{1-I_{t}} e^{-\phi_{I}} I_{t}$, i.e. inflation follows the LG-twisted autoregressive process. Inflation mean-reverts at a rate $\phi_{I}$, with the linearity-generating twist $\frac{1-I_{*}}{1-I_{t}}$ to ensure tractability. In addition, in case of a disaster, inflation jumps by an amount $J_{t}$, decomposed into $J_{t}=J_{*}+\widehat{J_{t}}$, where $J_{*}$ is the baseline jump in inflation, $\widehat{J}_{t}$ is the mean-reverting deviation of the jump size from baseline. This jump 
in inflation makes long term bonds particularly risky. It follows a twisted auto-regressive process and, for simplicity, does not jump during crises:

$$
\widehat{J}_{t+1}=\frac{1-I_{*}}{1-I_{t}} e^{-\phi_{J}} \widehat{J}_{t}+\varepsilon_{t+1}^{J}
$$

where $\varepsilon_{t+1}^{J}$ has mean $0 . \quad \varepsilon_{t+1}^{J}$ is uncorrelated with disasters but can be correlated with innovations in $I_{t}$.

Two notations are useful. First, call $\pi_{t}$ the variable part of the bond risk premium:

$$
\pi_{t} \equiv \frac{p_{t} \mathbb{E}_{t}\left[B_{t+1}^{-\gamma} F_{\S, t+1}\right]}{1+H_{\$}} \widehat{J}_{t}
$$

It is analogous to $-\widehat{H}_{i t}$ for stocks. The second notation is only useful when the typical jump in inflation $J_{*}$ is not zero and the reader is invited to skip it in the first reading. I parametrize $J_{*}$ in terms of a variable $\kappa \leq\left(1-e^{-\phi_{I}}\right) / 2$, called the inflation disaster risk premium:

$$
\frac{p_{t} \mathbb{E}_{t}\left[B_{t+1}^{-\gamma} F_{\$, t+1}\right] J_{*}}{1+H_{\$}}=\left(1-I_{*}\right) \kappa\left(1-e^{-\phi_{I}}-\kappa\right)
$$

i.e., in the continuous time limit: $p_{t} \mathbb{E}_{t}\left[B_{t+1}^{-\gamma} F_{\S, t+1}\right] J_{*}=\kappa\left(\phi_{I}-\kappa\right)$. A high $\kappa$ means a high central jump in inflation if there is a disaster. For most of the paper it is enough to think that $J_{*}=\kappa=0$.

Given this, we have:

Theorem 1 (Bond prices) In the limits of small time intervals, the nominal short term rate is $r_{t}=\delta-H_{\$}+I_{t}$, and the price of a nominal zero-coupon bond of maturity $T$ is:

$$
Z_{t}^{1}(T)=Z_{t}^{0}(T) Z_{t}^{*}(T)
$$

where $Z_{t}^{0}(T)$ is the bond price in the original $R B C$ economy, and $Z_{\$ t}^{*}(T)$ is the price in an endowment disaster economy:

$$
Z_{t}^{*}(T)=e^{-\left(\delta-H_{\S}+I_{* *}\right) T}\left(1-\frac{1-e^{-\psi_{I} T}}{\psi_{I}}\left(I_{t}-I_{* *}\right)-\frac{\frac{1-e^{-\psi_{I} T}}{\psi_{I}}-\frac{1-e^{-\psi_{J} T}}{\psi_{J}}}{\psi_{J}-\psi_{I}} \pi_{t}\right),
$$


where where $I_{t}$ is inflation, $\pi_{t}$ is the bond risk premium, $I_{* *} \equiv I_{*}+\kappa, \psi_{I} \equiv \phi_{I}-2 \kappa$, $\psi_{J} \equiv \phi_{J}-\kappa$, and $\kappa$ parametrizes the permanent risk of a jump in inflation (13).

Proof. The value of $Z_{t}^{*}(T)$ is in Gabaix. Because the inflation process is independent of the RBC shocks, we have the decomposition $Z_{t}^{1}(T)=Z_{t}^{0}(T) Z_{t}^{*}(T)$, with:

$$
\begin{aligned}
& Z_{t}^{0}(T)=\mathbb{E}\left[\rho_{0}^{T} C_{0 t+T}^{-\gamma} / C_{0 t}^{-\gamma}\right]=\text { Price of a bond in regular economy with no disaster } \\
& Z_{t}^{*}(T)=\frac{\mathbb{E}\left[\mathcal{D}_{t+T}^{-\gamma} / \mathcal{D}_{t}^{-\gamma}\right]}{\mathbb{E}\left[\mathcal{D}^{1-\gamma}\right]^{T}}=\text { Price of a bond in a disaster endowment economy }
\end{aligned}
$$

Given that the disaster model has nice tractable expressions and realistic bond prices (as argued in Gabaix 2009), the new model has the same properties.

\subsection{Stock prices: Why is $Q$ volatile and unrelated to investment?}

Without adornment, stock prices have be too little volatility. Hence, it is useful to incorporate some elements from Gabaix (2010). In that model, a firm's cash-flows drop in a disaster much more than the rest of the economy. To incorporate this idea, consider the following view.

The consumption good in the economy is a Dixit-Stiglitz aggregate:

$$
\begin{aligned}
K_{t+1} & =\left(\left(1-\delta_{K}\right) K_{t}+I_{t}\right) \cdot \Delta_{t+1} \\
A_{t+1} & =A_{t} \cdot \Delta_{t+1} \\
Y_{t} & =\left(\int_{0}^{1} Q_{i}^{1 / \psi} d i\right)^{\psi} \text { with } Q_{i}=A K_{i}^{\alpha} L_{i}^{1-\alpha}
\end{aligned}
$$

Each firm is a Dixit-Stiglitz monopolist. So, monopoly profits are: $D_{t}=(\psi-1) Y_{t}$. We assume that corrective taxes and lump-sum rebates are in place to lead to the first-best allocation. 
If there's a disaster, expropriation of rents (not capital) by $F_{t}$. So earnings are:

$$
\begin{aligned}
D_{i t} & =(\psi-1) Y_{i t} \Delta_{0}^{\pi} \ldots \Delta_{t}^{\pi} \\
\Delta_{t}^{\pi} & = \begin{cases}1 & \text { in normal times } \\
0 \text { with probability } 1-F_{t}, \text { otherwise } 1 & \text { if disaster }\end{cases}
\end{aligned}
$$

Using the stochastic discount factor

$$
M_{t}=\rho^{t} C_{t}^{-\gamma}
$$

The present value future profits is

$$
V_{t}^{\pi}=\mathbb{E}_{t}\left[\sum_{s=0}^{\infty} \frac{M_{t+s}}{M_{t}} D_{t+s}\right]
$$

We model time-varying riskiness of a firm as captured by its resilience:

$$
H_{t} \equiv p_{t} \mathbb{E}_{t}\left[B_{t+1}^{-\gamma} F_{t}-1\right]
$$

which we decompose

$$
H_{t}=H_{*}+\widehat{H}_{t}
$$

where $\widehat{H}_{t}$ follows the LG process:

$$
\widehat{H}_{t+1}=\frac{1+H_{*}}{1+H_{t}} e^{-\phi_{H}} \widehat{H}_{t}+\varepsilon_{t+1}^{H}
$$

Under those conditions, the value of pure profits is:

$$
\begin{aligned}
V_{t}^{\pi} & =\frac{(\psi-1) Y_{t}}{r_{e}}\left(1+\frac{\widehat{H}_{t}}{r_{e}+\phi}\right) \\
r_{e} & =R-\ln \left(1+H_{*}\right)
\end{aligned}
$$


The full value of the corporate sector is:

$$
V_{t}=V_{t}^{\pi}+K_{t}=\frac{(\psi-1) Y_{t}}{r_{e}}\left(1+\frac{\widehat{H}_{t}}{r_{e}+\phi}\right)+K_{t}
$$

The first part, $V_{t}^{\pi}$, is the capitalized present value of pure profits. The second, $K_{t}$, is the value of the physical capital in place.

Tobin's $Q$ Tobin's $Q$ is defined as the market value of equity, divided by the physical price of assets.

$$
Q_{t}=\frac{V_{t}}{K_{t}}=1+\frac{(\psi-1)}{r_{e}}\left(1+\frac{\widehat{H}_{t}}{r_{e}+\phi}\right) \frac{Y_{t}}{K_{t}}
$$

A central paradox in macro-finance is that $Q$ seems unrelated to investment (see the references in Philippon 2009). This is exactly what happens in this model. Investment is always equal to the RBC level of investment. This meshes well with the evidence from Philippon (2009), who finds that the bond market interest rate predicts investment, but not the stock market $Q$. The reason is that more investment shows up as more $K_{t}$, which can be costlessly replaced (adding adjustment costs to physical capital would not change the logic of the model). In this model, a higher $\widehat{H}_{t}$ simply signifies a higher present value of rents. But it is not correlated with investment.

There is a way to introduce a correlation with investment: if high stock market valuations spur entrepreneurship and the creation of new ideas, which can earn patents and new rents. This path is not modelled in this paper because it is likely to be small and because of the small correlation between investment and Tobin's Q in the aggregate. I note that this might be for the following reason: suppose that stock market valuations are very high $\left(\widehat{H}_{t}\right.$ is high); then, it is tempting for a would-be entrepreneur to start a firm, and, after say a 7-year lag, bring it to the stock market. However, in 7 years, it is very likely that will have meanreverted towards 0 (it will be, roughly, equal to $e^{-7 \phi} \widehat{H}_{t}$, with $\phi \simeq 13 \%$, so about $0.4 \widehat{H}_{t}$ ). That force will dampen the impact of the stock market. 


\subsection{Model calibration}

We take most numbers from the calibration in Gabaix (2010), which itself takes many numbers from Barro and Ursua (2008).

Table 1: Variables Used in the Calibration

\begin{tabular}{ll} 
Variables & Values \\
\hline \hline Time preference, risk aversion & $\rho=6.6 \%, \gamma=4$ \\
Growth rate of consumption and dividends & $g=g_{i D}=2.5 \%$ \\
Volatility of dividends & $\sigma_{D}=11 \%$ \\
Probability of disaster, Recovery rate of $C$ after disaster & $p=3.63 \%, \bar{B}=0.66$ \\
Recovery rate of stocks & $F_{*}=\bar{B}, \sigma_{F}=10 \%, \phi_{H}=13 \%$ \\
Inflation: Typical value, Volatility, Speed of mean-reversion & $I_{*}=3.7 \%, \sigma_{I}=1.5 \%, \phi_{I}=18 \%$ \\
Jump in Inflation: Typical value, Volatility, Speed of mean-reversion & $J_{*}=2.1 \%, \sigma_{J}=15 \%, \phi_{J}=92 \%$
\end{tabular}

We take $\psi=1.2$, so the mark up is about $20 \%$. Because $r_{e}=5 \%$, the typically $P / D$ ratio is 20 . The total firm value is

$$
V_{t}=V_{t}^{\pi}+K_{t}=\frac{(\psi-1) Y_{t}}{r_{e}}+K_{t}
$$

we find $V_{t}^{\pi} / Y_{t}=(\psi-1) / r_{e}=4$. By the usual calibration, $K / Y=4$. So, half of the firm market valuation is for physical capital while the rest is for the present value of rents.

With a debt/equity of about $50 \%$, we find a volatility of the stock market of about $15 \%$ a year. I conclude that the model calibrates quite well.

\section{Extension: Disasterizing Other Economies}

The same idea can be used for other economies. Let me illustrate the disasterization procedure with two other types of economies. 


\subsection{Economies with Habits}

Suppose the preferences are:

$$
u\left(C_{t}, H_{t}, L_{t}\right)=\frac{v\left(C_{t}, H_{t}\right)^{1-\gamma}}{1-\gamma} \phi(L)
$$

where $H_{t}$ is a habit variable, and $v(C, H)$ is homogenous of degree one. The habit process follows:

$$
H_{t+1}=f\left(H_{t}, C_{t}\right)
$$

for a function $f$. For instance, $f(H, C)=\beta H+(1-\beta) C$. We need the disasterized economy to be a rescaling of the original economy. Hence, the new disasterized economy keeps the same utility function, but the habit process must be:

$$
H_{t+1}=f\left(H_{t}, C_{t}\right) \Delta_{t+1}
$$

The reason is that $H_{t+1}$ is a stock variable. Economically, after a disaster, people revise their habits ("aspiration level" and the like) downwards.

The condition on the rate of time preferences $(7)$ is the same.

\subsection{Monetary Economies with Sticky Prices}

With sticky prices, things remain the same, except that "level" variables have to adjust. For instance, after a disaster of $20 \%$, the neoclassical wage should fall by $20 \%$. Hence, in a disasterized economy with sticky prices, right after a disaster, all wages have to fall by $20 \%$. Formally, if $w_{i t}^{0}$ is the real wage in firm $i$ at time $t$ in the non-disaster economy, the real wages in the disasterized economy are:

$$
w_{i t}=\mathcal{D}_{t} w_{i t}^{0} \text {. }
$$

This device preserves the neutrality.

Likewise, in a quantity theory of money and and in its sticky-price cousins, the stock of 
money $M_{t}$ must fall by $20 \%$ during a disaster. Formally, we must have:

$$
M_{t}=\mathcal{D}_{t} M_{t}^{0}
$$

Hence, the government removes some of the "excess liquidity" during the disaster.

More generally, if the price level can jump during disaster, we must have:

$$
\frac{M_{t}}{p_{t}}=\mathcal{D}_{t} \frac{M_{t}^{0}}{p_{t}^{0}}
$$

and the nominal wages (called here $w_{i t}^{\$}$ ) must follow:

$$
\frac{w_{i t}^{\$}}{p_{t}}=\mathcal{D}_{t} \frac{w_{i t}^{\$}}{p_{t}^{0}}
$$

\section{Conclusion}

This paper proposes a systematic way to enrich existing models by "disasterizing" economies; that is, by adding disasters to the model, in a careful way. A disaster of $20 \%$ should reduce productivity and the capital stock by the same $20 \%$. Then, the economies are very easy to solve. The resulting economy inherits the good business cycle properties from the macro model and the good asset pricing properties from the variable rare disater model.

In the current framework, the macro side of the economy affects asset prices, but not vice versa. It would be nice to extend it to the case where finance affects the macroeconomy. The availability of a simple model where macro and finance are integrated surely makes that goal more within reach. 


\section{References}

Abel, Andrew, "Asset Prices under Habit Formation and Catching up with the Joneses," American Economic Review Papers and Proceedings, 80(2), 38-42

Bansal, Ravi, and Amir Yaron, "Risks for the Long Run: A Potential Resolution of Asset Pricing Puzzles," Journal of Finance, 59 (2004), 1481-1509.

Bansal, Ravi, and Ivan Shaliastovich, "A Long-Run Risks Explanation of Predictability Puzzles in Bond and Currency Markets," Paper, Duke University, 2008.

Barro, Robert, "Rare Disasters and Asset Markets in the Twentieth Century," Quarterly Journal of Economics, 121 (2006), 823-866.

Barro, Robert, and José Ursua, "Macroeconomic Crises Since 1870," Brookings Papers on Economic Activity (2008), 255-335.

Barro, Robert, Emi Nakamura, Jón Steinsson, and José Ursua, "Crises and Recoveries in an Empirical Model of Consumption Disasters," Working Paper, Harvard, 2009.

van Binsbergen, Jules, Jesus Fernandez-Villaverde, Ralph Koijen, and Juan F. Rubio-Ramirez, "The Term Structure of Interest Rates in a DSGE Model with Recursive Preferences", Working Paper, SSRN, 2010.

Boldrin, Michele, Lawrence J. Christiano, and Jonas Fisher, 2001. "Habit Persistence, Asset Returns, and the Business Cycle," American Economic Review, 91(1), 149-166

Campbell, John Y., and John Cochrane, "By Force of Habit: A Consumption-Based Explanation of Aggregate Stock Market Behavior," Journal of Political Economy, 107 (1999), 205-251.

Cerra, Valerie and Sweta Chaman Saxena, "Growth Dynamics: The Myth of Economic Recovery," American Economic Review 2008, 98:1, 439-457.

Epstein, Larry G. and Stanley E. Zin "Substitution, Risk Aversion, and the Temporal Behavior of Consumption and Asset Returns: A Theoretical Framework," Econometrica, 57 (1989), 937-969.

Gabaix, Xavier, "A Unified Theory of Ten Financial Puzzles", Working Paper, SSRN, 2007.

Gabaix, Xavier, "Linearity-Generating Processes: A Modelling Tool Yielding Closed Forms for Asset Prices," Working Paper, NYU, 2009.

Gabaix, Xavier, "Variable Rare Disasters: An Exactly Solved Framework for Ten Puzzles in Macro-Finance" Working Paper, NYU, 2010. 
Gourio, Francois, "Disasters and Recoveries," American Economic Review, Papers and Proceedings, 98 (2008), 68-73.

Gourio, Francois, "Disaster Risk and Business Cycles," Working Paper, Boston University, 2010.

Hansen, Lars, Thomas J. Sargent, Thomas D. Tallarini, Jr., "Robust Permanent Income and Pricing," Review of Economic Studies, Vol. 66, No. 4 (1999), pp. 873-907.

Jermann, Urban J., 1998. "Asset Pricing in Production Economies," Journal of Monetary Economics, 41, 257-275.

Longstaff, Francis, and Monika Piazzesi, "Corporate Earnings and the Equity Premium," Journal of Financial Economics, 74 (2004), 401-421.

Philippon, Thomas, "The Bond Market's q", Quarterly Journal of Economics, 2009, 124(3), 1011-56.

Tallarini, Thomas, 2000. "Risk-Sensitive Real Business Cycles," Journal of Monetary Economics, 45(3), 507-532.

Uhlig, Harald, "Explaining Asset Prices with External Habits and Wage Rigidities in a DSGE Model," American Economic Review, Papers and Proceedings, 97 (2007), 239-43.

Veronesi, Pietro, "The Peso Problem Hypothesis and Stock Market Returns," Journal of Economic Dynamics and Control, 28 (2004), 707-725.

Wachter, Jessica, "Can Time-Varying Risk of Rare Disasters Explain Aggregate Stock Market Volatility?," NBER Working paper 14386, 2009. 